\title{
Daily Emotions and Stuttering: What Is the Relation?
}

\author{
Shanley Treleaven ${ }^{1,2}$, Anthony Buhr', Barbara Kucharski', Geoffrey Coalson ${ }^{2}$ \\ ${ }^{1}$ Department of Communicative Disorders, University of Alabama, LA; ${ }^{2}$ Department of Communicative Disorders, Louisiana State University, LA, USA
}

The purpose of this study was to examine the relation between daily emotions and stuttering. Daily data was acquired over an academic year from a three-year-old boy near onset of stuttering. The boy's caregiver provided daily ratings regarding fluency and emotionality of the child during the four greatest emotional events of the child's day. Each event was rated with respect to (a) event intensity, (b) emotional intensity, and (c) stuttering frequency. Results showed that daily ratings of stuttering frequency, as reported by the child's caregiver, were related to event intensity rather than the child's emotional intensity. Emotional intensity was related to stuttering frequency for negative emotions only. Thus, event intensity may contribute to both emotional arousal and stuttering.

Keywords: Daily emotional events, Developmental stuttering, Preschool-aged child

\section{INTRODUCTION}

A number of studies have examined emotional factors in developmental stuttering [13]. Many developmental factors have been investigated with cross-sectional designs [e.g., 4,5], in which children who stutter (CWS) are compared to children who do not stutter (CWNS). Such studies include questionnaire data from parents regarding their child's temperament $[4,6,7]$, with others focusing on physiological [8] or behavioral [9] measures of emotional reactivity and/or emotion regulation. However, current research has not yet determined the relation between daily emotional events and stuttering. This unit of time is a clinically relevant unit of time because the stuttering is known to vary at a number of timescales, including across hours in a day and across days of the week $[10,11]$. Thus, the present study examined caregiver reports regarding daily emotional events and stuttering.

\section{Emotional arousal and regulation in children who stutter}

Empirical studies have reported that various aspects of emotional arousal and emotion regulation differ between CWS and CWNS, as reported by parents on standardized questionnaires [4,6,7,12,13]. For example, Anderson et al. [4] found CWS exhibit less adaptability, less distractibility, and less rhythmicity than fluent peers. Eggers et al. [12] reported that CWS scored higher on anger and frustration on interrupted tasks, positive excitement when anticipating a forthcoming, pleasurable activity, and exhibited excess motor movements like nail biting, fidgeting and blinking. Karrass et al. [7] reported greater emotional reactivity, greater difficulty regulating emotions, and lower attention regulation for CWS. Seery et al. [13] reported that CWS exhibit lower adapt-

\section{(}
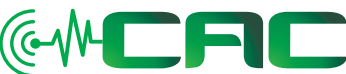

Received: October 11, 2018

Revision: December 17, 2018

Accepted: December 24, 2018

Correspondence:

Shanley Treleaven

Department of Communication Sciences and Disorders, Louisiana State University, 2403 Brightside Drive Apt. 1, BATON ROUGE, USA

Tel: +2059374830

Fax: +225-578-2995

E-mail: strele1@Isu.edu

Presented at the American Speech and Hearing Association Conference. Philadelphia, Pennsylvania, November 2016.

We would like to acknowledge the family who participated in this study. We would also like to acknowledge Shanika Thomas, Hunter Steiner and Annie Counts for their data collection and processing efforts.

C 2018 The Korean Association of SpeechLanguage Pathologists

This is an Open Access article distributed under the terms of the Creative Commons Attribution NonCommercial License (http://creativecommons.org/ licenses/by-nc/4.0/) which permits unrestricted noncommercial use, distribution, and reproduction in any medium, provided the original work is properly cited. 
ability, reduced attention span, more negative quality of mood, and higher activity levels compared with their nonstuttering peers. These combined data suggest that CWS, as a group, may differ in certain aspects of temperament that could potentially contribute to the onset, persistence, and/or behavior of stuttering. One possibility is that children with more emotionally reactive temperaments are more likely to react to emotionally-arousing events within the environment.

\section{Environmental factors affecting fluency}

Stressful or challenging events in the environment are often likely to elicit an emotional response in a child, particularly for children with a temperamental proclivity to emotional reactivity [14]. Such events could also be accompanied by an increase in speech disfluencies. Anecdotal evidence indicates that stuttering is often accompanied by emotional arousal (either positive or negative), as reports from parents of CWS note variation in stuttering that occurs within a day or a week with changes in emotional arousal $[10,15]$. However, the link between emotional arousal and stuttering is still unclear. Although previous studies have examined emotions elicited from stressors in the laboratory [8], and suggested a possible relationship between CWS and inefficient emotion regulation in negative emotional responses [9], a causal link between emotional arousal and stuttering behaviors has not been established.

The current study was undertaken to investigate the link between daily emotions and stuttering in a preschool-age child. The caregiver was instructed to identity the four most challenging/arousing events each day and then rate the associated level of emotional arousal and frequency of stuttering.

The two questions investigated in this study are as follows:

1) Is stuttering related to the intensity of daily emotional events?

2) Is stuttering related to emotional intensity during daily emotional events?

\section{METHODS}

\section{Participant}

A preschool-aged child (aged 3:4) near onset of stuttering was identified for participation in this study. Based on parent report, the child exhibited precocious language development, was considered by his mother to be emotionally reactive, and had a family history of stuttering.

During the initial assessment, the child's language develop-
Table 1. Standardized speech and language measures

\begin{tabular}{lccccc}
\hline Test & PPVT-2 & EVT-2 & CAAP-2 & GFTA-2 & TELD-3 \\
\hline Standard score & 104 & 104 & 109 & 116 & 81 \\
Percentile & 61 & 61 & 69 & 81 & 10 \\
\hline
\end{tabular}

PPVT-4, Peabody Picture Vocabulary Test, Fourth Edition; EVT-2, Expressive Vocabulary Test, Second Edition; CAAP-2, Clinical Assessment of Articulation and Phonology, Second Edition; GFTA-2, Goldman-Fristoe Test of Articulation, Second Edition; TELD-3, Test of Early Language Development, Third Edition.

ment and temperament was assessed using the Peabody Picture Vocabulary Test, Fourth Edition [16], Expressive Vocabulary Test, Second Edition [17], Goldman-Fristoe Test of Articulation, Second Edition [18], Clinical Assessment of Articulation and Phonology, Second Edition [19], Test of Early Language Development, Third Edition [20], Children's Behavior Questionnaire [21], and KiddyCat [22]. Standard scores are presented in Table 1 . The child's speech, language and vocabulary skills appeared to be within normal limits for his age with the exception of language skills measured by the TELD3. However, the child became noncompliant during this final measure, expressing displeasure due to the variability of the test activities (i.e., exchanging the easel for manipulatives). This may, instead, be an indication of the child's temperament [23] rather than language abilities. After gathering weekly speech samples with this child, however, it is the authors' professional assertion that the participant's speech, language and vocabulary skills were all within normal limits.

The child did not receive speech therapy for the first 13 weeks of the study. Instead, his caregivers were counseled by the first three authors. This counseling advised indirect speech therapy techniques such as adherence to routine $[11,24]$. During the final half of the study (week 18 to week 27), when he began to receive speech therapy services from the University of Alabama Speech and Hearing Center, both direct [25] and indirect speech therapy practices were implemented.

\section{Daily data}

Upon consent, parents first completed a novel intake questionnaire (Appendix A). In addition, a novel questionnaire was designed for this study to assess daily emotional events and associated stuttering (Appendix B). All components were measured on a 1-7 scale (7 highest) except valence, for which the caregiver circled whether each emotional event was positive or negative. Caregivers chose the four most intense emotional events each day and rated the 1) valence, 2) intensity of 
the event, 3) intensity of the child's emotion, 4) duration of the emotion, and 5) frequency of stuttering. Instructions to caregivers specified the intensity of the event as the precursor to emotions and any related stuttering. The adults who interacted with the child daily completed these questionnaires, specifically the child's mother and grandmother. However, the child's mother completed more than $90 \%$ of the questionnaires across the study. Daily questionnaires were returned to the clinic at weekly visits for 27 weeks, from September 2015 through April 2016.

\section{Data analysis}

Mixed model analysis using R statistical software [26] with the statistical package lme4 [27] were used to evaluate study hypotheses. Degrees of freedom for planned comparisons were calculated based on the Satterthwaite approximation using the statistical package lmerTest [28]. For each model, independent variables (e.g., caregiver rating of event intensity, 1-7) of interest were used in the base model to predict the dependent variable (e.g., caregiver rating of stuttering frequency, 1-7), along with covariates. Week was used as a time variable. Interactions were included in a model if significant. For the lme4 package, the null distribution is a t-distribution showing a t-statistic, approximated by the regression parameter (estimate) divided by the standard error (SE) of the estimate.

\section{RESULTS}

\section{Question 1: Is stuttering related to the intensity of daily emotional events?}

A mixed model showed that event intensity was related to stuttering, $\beta=0.313, t(695)=3.777, p<0.001$, indicating that the event intensity was significantly related to the level of the child's observed stuttering.

\section{Question 2: Is stuttering related to emotional intensity during daily emotional events?}

The child's overall emotional intensity during an emotional event was not related to observed stuttering, $\beta=-0.029, t(696)=$ $0.136, p=0.892$. However, an interaction between emotional intensity and valence was present, with emotional intensity being related to observed stuttering for negative emotions only, $\beta=0.528, t(695)=2.147, p=0.032$. This finding indicates that as negative emotional intensity increased, stuttering increased.

Finally, observed stuttering reported by the caregiver did not change across the weeks of the study, $\beta=0.015 t(441)=$ $0.581, p=0.562$. However, a three-way interaction was detected between emotion intensity, valence, and week, $\beta=-0.028$, $t(694)=2.165, p=0.031$, indicating that the relation between negative emotional intensity and stuttering frequency decreased as the weeks progressed in the study.

\section{DISCUSSION}

\section{Event intensity}

Per daily caregiver observations, event intensity was related to observed stuttering. However, this was not mediated by emotional intensity. Emotional intensity was related to observed stuttering for negative emotion, and this diminished from the beginning to the end of the study.

Results also showed that event intensity, as reported by caregivers, was significantly related to observed stuttering, as also reported by caregivers. This finding suggests that the intensity of daily events (e.g., moving into a new home; putting on shoes) can have an impact on speech fluency, consistent with much anecdotal evidence [29] and theoretical suggestions [14]. Considering the indirect relation between emotional intensity and stuttering (i.e., only negative valence and only at the beginning of the study), this finding further suggests that emotional arousal need not function as a mediator between stressful events and stuttering, at least for the child in this study. Rather, it would appear that event intensity can influence stuttering independent of emotional arousal [30].

\section{Emotion intensity}

There was no main effect of caregiver-observed emotional intensity in relation to observed stuttering for the child in this study. This indicates that, overall, stuttering largely occurred in absence of any observable emotional arousal. However, negative emotion was related to stuttering, but only at the beginning of study, indicating that when stuttering was accompanied by emotion, it tended to be negative. This may relate to the conclusions found by Johnson et al. [9], where only negative emotional regulation differences were found in CWS. Nevertheless, this finding does not imply directionality or causation. For example, rather than the child having a more difficult time producing fluent speech during negative emotional states (e.g., crying), the caregiver might have been more likely to notice disfluency when the child was expressing negative emotion.

The caregiver's reports of negative emotional intensity be- 
came less predictive of stuttering as the study progressed. This could reflect either change in the caregiver's perception of the child's stuttering or change in how the child responded to emotionally-arousing events. Regarding this latter possibility, the child's emotion regulation capabilities could have developed during this time, particularly for events that were likely to elicit negative emotion.

\section{Clinical considerations}

Indirect therapy methods, such as suggesting slowed speech, presenting stuttering in a neutral, non-negative light and giving the child a predictable daily routine $[11,24]$, were implemented throughout the study. During the second half of the study period, the Lidcombe program for stuttering was administered by the clinical supervisor. Each week, clinicians and researchers counseled the caregiver regarding the child's stuttering. The child's stuttering also happened to change across the last 11 weeks of the study. These changes included increased frequency of repetitions in lieu of prolongations, displaying different, temporary secondary behaviors such as kicking and differentiating breath patterns during speech, and decreasing neck tension during disfluent speech. One interpretation of this observation is that intervention had a causal influence on the child's stuttering. Another interpretation may suggest the child continued to develop, and by the latter half of the study, ceased to respond with such intensity to negative emotionally arousing events. Another possibility is that empowering the caregivers to be open about stuttering with the child may have changed the family dynamic such that emotionally-arousing events were less intense. Finally, it is possible that reporting daily events affected implementation of indirect therapy methods, causing caregivers to notice and thus reduce environmental stressors that place increased demands upon the child. More research is needed to explore these possibilities.

\section{Limitations}

One limitation of the study is that the caregiver was asked to identify emotionally arousing events, as the caregiver could have been more likely to identify events if they involved negative emotion or the presence of stuttering. A preferable study design would have identified specific times during the day for caregivers to make ratings. Another limitation is that the study was only conducted for two semesters, prior to knowing whether the child recovered from stuttering. Future studies acquiring data at daily and weekly timescales would benefit from establishing the duration of the study to encompass persistence or recovery.

\section{CONCLUSION}

This analysis of one child's stuttering did not find evidence that emotional arousal was related to the child's stuttering, but that situational factors such as the intensity of the event were significant factors. Although the study involved only one participant, the longitudinal design afforded data collection at daily and weekly timescales. Future studies should acquire data at such timescales to take into account the daily and weekly experiences of the child, and thus identify events that could bring about changes in behavior, including emotional arousal and/or stuttering.

\section{REFERENCES}

1. McAllister J. Behavioral, emotional and social development of children who stutter. Journal of Fluency Disorders. 2016;50:23-32.

2. Embrechts M, Ebben H, Franke P, van de Poel C. Temperament: a comparison between children who stutter and children who do not stutter. In: Bosshardt HG, Yaruss JS, Peters H. (eds.) Proceedings of the third world congress on fluency disorders: Theory, research, treatment and self-help. Nijmegen, The Netherlands: Nijmegen Press; 2000. p. 557-562.

3. Arnold HS, Conture EG, Key AP, Walden T. Emotional reactivity, regulation and childhood stuttering: a behavioral and electrophysiological study. Journal of Communication Disorders. 2011;44:276293.

4. Anderson JD, Pellowski MW, Conture EG, Kelly EM. Temperamental characteristics of young children who stutter. Journal of Speech Language and Hearing Research. 2003;46:1221.

5. Anderson JD, Pellowski MW, Conture EG. Childhood stuttering and dissociations across linguistic domains. Journal of Fluency Disorders. 2005;30:219-253.

6. Eggers K, Nil LFD, Bergh BRVD. Temperament dimensions in stuttering and typically developing children. Journal of Fluency Disorders. 2010;35:355-372.

7. Karrass J, Walden TA, Conture EG, Graham CG, Arnold HS, Hartfield KN, et al. Relation of emotional reactivity and regulation to childhood stuttering. Journal of Communication Disorders. 2006; 39:402-423.

8. Jones RM, Buhr AP, Conture EG, Tumanova V, Walden TA, Porges SW. Autonomic nervous system activity of preschool-age children who stutter. Journal of Fluency Disorders. 2014;41:12-31.

9. Johnson KN, Walden TA, Conture EG, Karrass J. Spontaneous regulation of emotions in preschool children who stutter: preliminary findings. Journal of Speech Language and Hearing Research. 2010;53:1478. 
10. Yaruss J. Clinical implications of situational variability in preschool children who stutter. Journal of Fluency Disorders. 1997;22:187203.

11. Yaruss JS, Coleman C, Hammer D. Treating preschool children who stutter: description and preliminary evaluation of a familyfocused treatment approach. Language Speech and Hearing Services in Schools. 2006;37:118.

12. Eggers K, De Nil LF, Van den Bergh BR. The Efficiency of attentional networks in children who stutter. Journal of Speech, Language, and Hearing Research. 2012;55:946-959.

13. Seery CH, Watkins RV, Mangelsdorf SC, Shigeto A. Subtyping stuttering II: contributions from language and temperament. Journal of Fluency Disorders. 2007;32:197-217.

14. Walden TA, Frankel CB, Buhr AP, Johnson KN, Conture EG, Karrass JM. Dual diathesis-stressor model of emotional and linguistic contributions to developmental stuttering. Journal of Abnormal Child Psychology. 2011;40:633-644.

15. Yairi E, Ambrose NG. Early childhood stuttering for clinicians by clinicians. Austin, TX: Pro-ed; 2005.

16. Dunn A, Dunn A. Peabody picture vocabulary test. 4th ed. Circle Pines, MN: American Guidance Service, 2007.

17. Williams K. Expressive vocabulary test. 2nd ed. Circle Pines, MN: American Guidance Service, 2007.

18. Goldman R, Fristoe M. Goldman-Fristoe test of articulation. 2nd ed. Circle Pines, MN: American Guidance Service, 2000.

19. Secord W, Donohue J. Clinical assessment of articulation and phonology. 2nd ed. Greenville, SC: Super Duper Publications, 2013.

20. Hresko W, Reid D, Hammill D. Test of early language develop- ment. 3rd ed. Austin, TX: PRO-ED, 1999.

21. Rothbart MK, Ahadi SA, Hershey KL, Fisher P. Investigations of temperament at three to seven years: The Childrens Behavior Questionnaire. Child Development. 2001;72:1394-1408.

22. Vanryckeghem M, Brutten G. KiddyCat: Communication attitude test for preschool and kindergarten children who stutter. San Diego, CA: Plural Publishing Incorporated, 2007.

23. Ntourou K, Conture EG, Lipsey MW. Language abilities of children who stutter: a meta-analytical review. American Journal of Speech-Language Pathology. 2011;20:163.

24. Millard SK, Nicholas A, Cook FM. Is parent-child interaction therapy effective in reducing stuttering? Journal of Speech Language and Hearing Research. 2008;51:636.

25. Onslow M, Packman A, Harrison E. The Lidcombe program of early stuttering intervention: a clinicians guide. Austin, TX: ProEd, 2003.

26. R Development Core Team. R: A language and environment for statistical computing. Vienna, Austria: Foundation for Statistical Computing, 2009.

27. Bates D, Mächler M. lme4: Linear mixed-effects models using S4 classes. R package version 3.1.3, 2009.

28. Kuznetsova A, Brockhoff $\mathrm{P}$, Chistensen R. ImerTest. R package version 2.0-3.0, 2012.

29. Blood I, Wertz H, Bennett S, Blood G, Simpson K. Effects of life stressors and daily stressors on stuttering. Journal of Fluency Disorders. 1997;22:87.

30. Buhr AP, Scofield J, Eyer JC, Walden TA. Cued self-awareness and speech fluency. Speech, Language and Hearing. 2017;20:187-195. 


\section{Appendix A}

\section{University of Alabama}

Client ID:

\section{Intake Checklist}

"Contributing factors to stuttering development in preschool-age and school-age children"

\section{Instructions}

Please circle the answer that best completes the statements below:

1. The current date: year_ month day

2. My child's birth date:

year month day

Chronological age:

year month day

3. To the best of my knowledge, I first noticed my child's stuttering:

year month day

4. In my opinion, the onset of my child's stuttering was affected by the following event(s):

a.

b.

5. Other members of my immediate family who stutter now or have stuttered in the past include:
a.
b.
c.
d.
e.

6. If your child has received stuttering treatment from stuttering in the past, please provide the dates corresponding to the beginning and end of treatment:

From:

year month day

To: year month day 


\section{Appendix B}

\section{University of Alabama - Daily Events Checklist}

Client ID:

Date:

Instructions: Fill out the table below with at least 4 specific emotional events for the past 24 hours. Please fill out this table the same time every day. In addition, consider for today only your child's general level of emotional arousal and stuttering, and whether routine was typical:

1. My child's general level of emotional arousal in the last 24 hours, on a scale of 1-7, from no arousal to peak arousal is:

2. My child's general level of stuttering in the last 24 hours, on a scale of 1-7, from no stuttering to peak stuttering, is:

3. Routine today was typical: Morning? Yes No Evening? Yes No Meals? Yes No People? Yes No

\begin{tabular}{|c|c|c|c|c|c|c|c|c|}
\hline & $\begin{array}{l}\text { Event that led } \\
\text { to arousal }\end{array}$ & $\begin{array}{l}\text { Positive or } \\
\text { negative? } \\
\text { (circle one) }\end{array}$ & $\begin{array}{l}\text { Intensity of event } \\
\text { Rate (1-7) }\end{array}$ & $\begin{array}{l}\text { Observed } \\
\text { emotion(s) }\end{array}$ & $\begin{array}{l}\text { Intensity of } \\
\text { emotion } \\
\text { Rate (1-7) }\end{array}$ & $\begin{array}{l}\text { Duration of } \\
\text { emotion } \\
\text { Rate (1-7) }\end{array}$ & $\begin{array}{l}\text { Observed } \\
\text { amount of } \\
\text { stuttering } \\
\text { Rate (1-7) }\end{array}$ & $\begin{array}{c}\text { Frustration } \\
\text { about stuttering } \\
\text { Rate (1-7) }\end{array}$ \\
\hline Event 1 & & $\begin{array}{l}\text { Positive } \\
\text { Negative }\end{array}$ & & & & & & \\
\hline Event 2 & & $\begin{array}{l}\text { Positive } \\
\text { Negative }\end{array}$ & & & & & & \\
\hline Event 3 & & $\begin{array}{l}\text { Positive } \\
\text { Negative }\end{array}$ & & & & & & \\
\hline Event 4 & & $\begin{array}{l}\text { Positive } \\
\text { Negative }\end{array}$ & & & & & & \\
\hline & $\begin{array}{l}\text { Examples } \\
\text { Minor } \\
\text { Not get treat } \\
\text { Woke from nap } \\
\text { Major } \\
\text { Birth in family } \\
\text { Death in family }\end{array}$ & & $\begin{array}{l}\text { 1-very minor } \\
\text { 2-somewhat minor } \\
\text { 3-minor } \\
\text { 4-not sure } \\
\text { 5-major } \\
\text { 6-somewhat major } \\
\text { 7-very major }\end{array}$ & $\begin{array}{l}\text { Examples } \\
\text { Crying } \\
\text { Laughter } \\
\text { Anger } \\
\text { Disgust } \\
\text { Anxiety } \\
\text { Agitated }\end{array}$ & $\begin{array}{l}\text { 1-no arousal } \\
\text { 2-little arousal } \\
\text { 3-some arousal } \\
\text { 4-not sure } \\
\text { 5-much arousal } \\
\text { 6-high arousal } \\
\text { 7-peak arousal }\end{array}$ & $\begin{array}{l}\text { 1-few seconds } \\
\text { 2-several seconds } \\
\text { 3-half minute } \\
\text { 4-full minute } \\
\text { 5-few minutes } \\
\text { 6-several minutes } \\
\text { 7-nearly an hour }\end{array}$ & $\begin{array}{l}\text { 1-no stuttering } \\
\text { 2-little stuttering } \\
\text { 3-some stuttering } \\
\text { 4-not sure } \\
\text { 5-much stuttering } \\
\text { 6-high stuttering } \\
\text { 7-peak stuttering }\end{array}$ & $\begin{array}{l}\text { 1-no frustration } \\
\text { 2-little frustration } \\
\text { 3-some frustration } \\
\text { 4-not sure } \\
\text { 5-much frustration } \\
\text { 6-high frustration } \\
\text { 7-peak frustration }\end{array}$ \\
\hline
\end{tabular}

